\title{
Particulate Matter Concentrations and Their Association With COVID-19 Related Mortality in Mexico During June 2020 Saharan Dust Event
}

\section{Gurusamy Kutralam-Muniasamy}

CINVESTAV-IPN

\section{Fermín Pérez-Guevara}

CINVESTAV IPN: Centro de Investigacion y de Estudios Avanzados del Instituto Politecnico Nacional Ignacio Elizalde Martínez

Centro Mexicano para la Produccion Mas Limpia-IPN

Shruti Venkata Chari ( $\nabla$ shrutifrnd@gmail.com )

Centro Mexicano para la produccion mas limpia

\section{Research Article}

Keywords: Air Pollution, PM2.5, PM10, Air quality index, Public health, Hazard quotient

Posted Date: March 17th, 2021

DOI: https://doi.org/10.21203/rs.3.rs-259561/v1

License: (c) (i) This work is licensed under a Creative Commons Attribution 4.0 International License. Read Full License 


\section{Particulate matter concentrations and their association with COVID-19 related mortality}

\section{in Mexico during June 2020 Saharan Dust event}

3 Gurusamy Kutralam-Muniasamy ${ }^{1}$, Fermín Pérez-Guevara ${ }^{1,2}$, Ignacio Elizalde Martínez ${ }^{3}$, Shruti

$5 \quad{ }^{1}$ Department of Biotechnology and Bioengineering, Centro de Investigación y de Estudios Avanzados del Instituto Politécnico Nacional, Ciudad de México, México.

$7 \quad{ }^{2}$ Nanoscience \& Nanotechnology Program, Centro de Investigación y de Estudios Avanzados del Instituto Politécnico Nacional, Ciudad de México, México.

${ }^{3}$ Instituto Politécnico Nacional (IPN), Centro Mexicano para la Producción más Limpia (CMP+L), Av. Acueducto s/n, Col. Barrio la Laguna Ticomán, Del Gustavo A. Madero, C.P. 07340, México, D.F., México.

$20 *$ Corresponding Author Mailing Address: Instituto Politécnico Nacional (IPN), Centro Mexicano

21 para la Producción más Limpia $(\mathrm{CMP}+\mathrm{L})$, Av. Acueducto s/n, Col. Barrio la Laguna Ticomán,

22 Del Gustavo A. Madero, C.P. 07340, México, D.F., México.

23 E-mail address: shrutifrnd@gmail.com Tel.: 57296000 Extn- 52612 
24 Keywords: Air Pollution; $\mathrm{PM}_{2.5} ; \mathrm{PM}_{10}$; Air quality index; Public health; Hazard quotient.

\section{Abstract}

The present study evaluated the impact of Saharan dust event on particulate matter (PM;

$27 \mathrm{PM}_{10}$ and $\mathrm{PM}_{2.5}$ ) concentrations by analyzing the daily average PM data between Saharan dust

28 days (June 23 - 29, 2020) and non-Saharan dust days (June 15 to June 22 and June 30 to July 12,

29 2020) for four major affected regions in Mexico and by comparing with three major previous

30 events (2015, 2018 and 2019). The results showed $\mathrm{PM}_{10}$ and $\mathrm{PM}_{2.5}$ concentrations were 2-5 times

31 higher during the Saharan dust event with the highest daily averages of $197 \mu \mathrm{g} / \mathrm{m}^{3}$ and $94 \mu \mathrm{g} / \mathrm{m}^{3}$,

32 respectively and exceeded the Mexican standard norm (NOM-020-SSA1-2014). When comparing

33 with the previous Saharan dust episodes of 2015, 2018 and 2019, the levels of $\mathrm{PM}_{10}$ and $\mathrm{PM}_{2.5}$

34 considerably increased and more than doubled across Mexico. The correlation analysis revealed a

35 positive association of PM levels with the number of daily COVID-19 cases and deaths during

36 Saharan dust event. Furthermore, the human health risk assessment showed that the chronic daily

37 intake and hazard quotient values incremented during Saharan dust days compared to non-Saharan

38 days, indicating potential health effects and importance of taking necessary measures to ensure

39 better air quality following the COVID-19 pandemic.

40

41

42

43

44

45

46 
1. Introduction

Air pollution remains a global environmental threat and a public health risk. The World

50 Health Organization (WHO) estimated that exposure to polluted air alone caused around 4.2

51 million deaths worldwide in 2016 (WHO 2018). Particulate matter (PM) is one of the most

52 common air pollutant which comprises particles of various sizes $\left(\mathrm{PM}_{10}\right.$ and $\left.\mathrm{PM}_{2.5}\right)$ with associated

53 adsorbed substances (i.e. chemicals and metals). PM can be naturally originated (i.e. sea spray,

54 volcanoes, forests, and deserts) and anthropogenic originated (i.e. vehicles, combustion, industry

55 and power plants) (Hernández-Escamilla et al. 2015; Ali-Khodja et al. 2017). With the increase in

56 anthropogenic activities and ambient PM concentrations, their exposure to short-term and long-

57 term period affects human health and contributes breathing problems, respiratory diseases, chronic

58 diseases, cancer and premature mortality (Kim et al. 2015; Loxham and Nieuwenhuijsen 2019).

59 The impact of desert dust events on the PM concentrations and human health have received

60 worldwide attention in the last decades. Sahara Desert is the largest source of atmospheric mineral

61 dust and dust storms are a common meteorological phenomenon, happening especially between

62 late Spring and early Fall, peaking in late June to mid-August (Querol et al. 2019; Çapraz and

63 Deniz 2020). It has been estimated that about 800 millions of metric tons of dust from North Africa

64 travel and impact across the Atlantic Ocean, the Mediterranean Sea and the Red Sea, to the

65 Caribbean, South America, North America, Europe and the Middle East every year (Querol et al.

66 2019; Çapraz and Deniz 2020). Owing to the frequent long-range transport of large amounts of

67 dust, a number of studies have evaluated the impact of Saharan dust events on PM concentrations

68 (Querol et al. 2009; Achilleos et al. 2014; Moroni et al. 2015; Dimitriou and Kassomenos 2018;

69 Querol et al. 2019). It is understood from these studies that Sahara dust events greatly increase the 
70 ambient concentration of PM contributing to air pollution and may be associated with adverse 71 health effects.

72 According to NOAA's (National Oceanic and Atmospheric Administration) Atlantic

73 Oceanographic and Meteorological Laboratory, the June 2020 Saharan dust event was around 60-

$7470 \%$ dustier than an average event happened in 20 years. Most notably, the June 2020 Saharan

75 dust occurred at a critical time when the world is already facing Coronavirus disease 2019

76 (COVID-19), a global health crisis. COVID-19 is an acute respiratory disease caused by SARS-

77 CoV-2 (WHO 2020); it has been suggested that environmental factors, such as ambient air

78 pollution, could increase the severity of the health outcomes (e.g., hospitalization and death)

79 among individuals with COVID-19 (Coker et al. 2020). Recent researchers have corroborated the

80 presence of SARS-CoV-2 viral RNA on coarse PM and associations with COVID-19 mortality

81 cases (Setti et al. 2020; Wu et al. 2020). Several studies identified positive association between

82 higher $\mathrm{PM}_{2.5}$ and $\mathrm{PM}_{10}$ and COVID-19 deaths globally (Yao et al. 2020; Wu et al. 2020). With the

83 rapid emergence of the novel COVID-19 disease, which by itself is a respiratory disease, it will be

84 important to evaluate the impact of June 2020 Saharan dust event on PM levels and to determine

85 if any relevant associations with COVID-19 cases and deaths. The Saharan dust event occurred

86 between June 23 and June 29, 2020 in Mexico, right after the withdrawal of COVID-19 lockdown,

87 has drawn our attention. Air pollution has been a primary issue in Mexico, exceeding the WHO

88 recommended level in relation to various types of air pollutants, including the PM, in most of its

89 major cities (Molina et al. 2019). The Saharan dust affected regions include the parts of

90 northeastern Mexico and Yucatan Peninsula (Fig. 1), where they already have higher levels of air

91 pollution due to industrialization and urbanization activities (González-Santiago et al. 2011;

92 Bretón et al. 2018; CONAGUA, 2020). Thus, the main objectives of this study are (1) to examine 
93 the relative contribution of Saharan dust on $\mathrm{PM}_{10}$ and $\mathrm{PM}_{2.5}$ concentrations, (2) to assess the

94 variations in PM concentrations when compared with previous major dust episodes (2015, 2018

95 and 2019), (3) to explore the association of PM concentrations with COVID-19 cases and deaths

96 and (4) to evaluate the human health risk associated with PM exposure via inhalation. To the best

97 of our knowledge, this is the first research to document the impact of Saharan dust event in relation

98 to $\mathrm{PM}$ levels $\left(\mathrm{PM}_{10}\right.$ and $\left.\mathrm{PM}_{2.5}\right)$ and human health in Mexico and during COVID-19 crisis.

\section{2. Methodology}

\section{$100 \quad 2.1$ Site description and data collection}

101

In this study, the PM levels $\left(\mathrm{PM}_{10}\right.$ and $\left.\mathrm{PM}_{2.5}\right)$ for a total of 28 days between June 15, 2020

102 and July 12, 2020 were assessed in four majorly hit regions of Mexico namely, Nuevo Leon,

103 Veracruz, Tabasco and Yucatan (Fig. 1b). The period between June 23 and June 29, 2020 when

104 the event took place in Mexico was considered as Saharan dust days, whereas the periods prior

105 (June 15 to June 22) and after the event (June 30 to July 12, 2020) were collectively considered as

106 non-Saharan dust days. For our analysis, we used daily concentrations of $\mathrm{PM}_{10}$ and $\mathrm{PM}_{2.5}$ for the

107 study period from 15 air monitoring stations located in Nuevo Leon $(\mathrm{n}=11)$, Veracruz $(\mathrm{n}=2)$,

108 Tabasco $(n=1)$ and Yucatan $(n=1)$, respectively. The details of the monitoring stations for the study

109 period are provided in Table 1. The previous major Saharan dust episodes in Mexico, recorded in

110 the years of 2015, 2018 and 2019 were considered for the comparison of PM levels with that of

111 2020. The PM data for Saharan dust events during 2015, 2018, 2019 and 2020 was downloaded

112 from the website of Sistema Nacional de Información de la Calidad del Aire, (SINAICA, 113 https://sinaica.inecc.gob.mx/index.php) operated by Instituto Nacional de Ecologia y Cambio 114 Climatico, Government of Mexico. 
116 the data of confirmed COVID-19 cases and deaths (June 15, 2020 to July 12, 2020) from the

117 official website of the Government of Mexico (https://coronavirus.gob.mx/datos/). We preferred

118 to carry out this analysis only for Nuevo Leon as the dataset available from monitoring stations

$119(\mathrm{n}=11)$ covers the wider province comparatively higher than other states selected in this study.

120 Additionally, it represents the third most populated region in Mexico. Statistical analysis was

121 conducted using Statistica software (version 8.0). The whole data set was varimax normalized to

122 minimize the number of variables with a high loading on each component. Correlation matrix with

$123 p<0.5,0.01,0.001$ values were obtained to investigate the relationships between the PM levels

124 and COVID-19 cases and deaths.

$125 \quad 2.2$ Air quality index

126

Air Quality Index (AQI) by USEPA (1999) was employed for the effective assessment of

127 air quality. We calculated $\mathrm{AQI}$ for $\mathrm{PM}_{10}$ and $\mathrm{PM}_{2.5}$ obtained from each monitoring stations using

128 the following equation:

129

$$
I_{p}=\frac{I_{H i}-I_{L o}}{B P_{H i}-B P_{L o}}\left(C_{p}-B P_{L o}\right)+I_{L o}
$$

Where, $I_{p}=$ index for pollutant $p ; C_{p}=$ rounded concentration of pollutant $p ; B P_{H i}=$ the breakpoint

131 that is greater than or equal to $C_{p} ; B P_{L o}=$ the breakpoint that is less than or equal to $C_{p} ; I_{H i}=$ the

$132 \mathrm{AQI}$ value corresponding to $B P_{H i} ; I_{L o}=$ the AQI value corresponding to $B P_{L o}$. The AQI ranges

133 from 0 to 500 and categorized into following six intervals: 0-50: Good (air quality is good with no

134 risk); 51-100: Moderate (air quality is acceptable; however, for some pollutants there may be a 135 moderate health concern like for people having respiratory diseases); 101-150: Unhealthy for 136 sensitive groups (members of sensitive groups may experience health effects); 151-200: Unhealthy 137 (everyone may begin to experience health effects); 201-300: Very unhealthy (health warnings of 
138 emergency conditions and the entire population is more likely to be affected) and 301-500:

139 Hazardous (everyone may experience more serious health effects).

\subsection{Human health risk assessment on exposure to particulate matter (PM10 and $\left.\mathbf{P M}_{2.5}\right)$}

$141 \quad$ 2.3.1 Exposure dose

142

Human health risk assessment (USEPA, 1989) was performed to understand the nature and

143 probability of adverse health effects in humans exposed to PM during the June 2020 Saharan dust

144 event. We concentrated on the health risk estimation through inhalation route for both children and

145 adults. Chronic daily intake (CDI) was estimated for assessing the human health risk upon 146 exposure to PM through inhalation pathway. It was calculated as follows (USEPA 2009):

$$
C D I_{\text {inh }}=C_{U C L} \times \frac{R_{\text {inh }} \times F_{\text {exp }} \times T_{\text {exp }}}{A B W \times T_{\text {avrg }}}
$$

148 where, $\mathrm{CDI}=$ chronic daily intake $\left(\mu \mathrm{g} \mathrm{kg}^{-1} \mathrm{day}^{-1}\right) ; R_{\text {inh }}=$ inhalation rate at $20 \mathrm{~m}^{3}$ day $^{-1}$ for adults 149 and $7.6 \mathrm{~m}^{3}$ day $^{-1}$ for children; $F_{\text {exp }}=$ exposure frequency (days year ${ }^{-1}$ ), in the present study 150 exposure frequency was considered as 28 days year ${ }^{-1}$ corresponding to the June 2020 Saharan dust 151 event; $T_{\text {exp }}=$ the exposure duration 6 years for children and 24 years for adult; $A B W=$ average 152 body weight, $15 \mathrm{~kg}$ for children and $70 \mathrm{~kg}$ for adults; $T_{\text {avrg }}=$ averaging time, for non-carcinogens $153 T_{\text {avrg }}=T_{\text {exp }} * 365$ days and for carcinogens $T_{\text {avrg }}=70 * 365$.

$$
\mathrm{C} \text { is the concentration of particulate matter }\left(\mu \mathrm{g} / \mathrm{m}^{3}\right) . C_{U C L} \text { estimates the reasonable }
$$
155 maximum exposure, which is the upper limit of the $95 \%$ confidence interval for the mean. $C_{U C L}$ 156 was calculated based on the Central Limit Theorem (Adjusted) by USEPA, 2002:

$$
C_{U C L}=\bar{X}+\left(Z+\frac{\beta}{6 \sqrt{n}}\left(1+2 \times z^{2}\right)\right) S T D / \sqrt{n}
$$

158 Where, $\bar{X}=$ arithmetic mean; $\mathrm{Z}=$ statistic constant $1.645 ; \beta=$ skewness; $\mathrm{n}=$ number of samples 159 and STD = standard deviation. 


\subsubsection{Risk characterization}

Risk assessment for the carcinogenic and non-carcinogenic risk of PM was calculated using

162 the parameter called hazard quotient (HQ), the ratio of CDI to reference dose (RfD) by using the

163 following equation:

Hazard Quotient $(\mathrm{HQ})=$ CDI/RfD (USEPA 1989, 2011)

HQ of 1.0 is considered safe. HQ that is $<1.0$ indicates a negligible risk, i.e. the pollutant is not likely to induce adverse health effects, even to a sensitive individual. HQ > 1.0 indicates that

167 there may be some risks to sensitive individuals as a result of exposure (USEPA 1989, 2011). 168 Given the lack of information regarding RfD of $\mathrm{PM}_{10}$ and $\mathrm{PM}_{2.5}$ in Mexico, we calculated RfD 169 using the following equation:

$170 \mathrm{RfD}=\mathrm{RfC}$ (inhalation reference concentration $\left.\mu \mathrm{g} / \mathrm{m}^{3}\right) \times$ Assumed inhalation $\mathrm{rate}\left(\mathrm{m}^{3} /\right.$ day) $\times 1 /$ $171 \quad \mathrm{BW}(\mathrm{kg})$

172 We used RfC values of $50 \mu \mathrm{g} / \mathrm{m}^{3}$ for $\mathrm{PM}_{10}$ and $5 \mu \mathrm{g} / \mathrm{m}^{3}$ for $\mathrm{PM}_{2.5}$ (de Oliveira et al. 2012; Li et al. 173 2017; Yunesian et al. 2019) in order to assess the probability of adverse health impacts.

\section{3. Results and discussion}

175 The daily average concentration of $\mathrm{PM}_{10}$ and $\mathrm{PM}_{2.5}$ during the June 2020 Saharan dust 176 event from 15 monitoring stations are shown in Figure 2 and 3. The daily average $\mathrm{PM}_{10}$ and $\mathrm{PM}_{2.5}$

177 levels were high during Saharan dust event and exceeded the annual limit of $75 \mu \mathrm{g} / \mathrm{m}^{3}$ and 45 $178 \mu \mathrm{g} / \mathrm{m}^{3}$ set up by the Mexican standard Norm (NOM-020-SSA1-2014; DOF 2014). It also exceeded 179 the WHO air quality guidelines for the annual mean concentrations of $50 \mu \mathrm{g} / \mathrm{m}^{3}$ and $25 \mu \mathrm{g} / \mathrm{m}^{3}$ for $180 \quad \mathrm{PM}_{10}$ and $\mathrm{PM}_{2.5}$, respectively (WHO 2006).

In general, the $\mathrm{PM}_{10}$ and $\mathrm{PM}_{2.5}$ were at low concentrations before the dust event. As shown 182 in Fig. 2 and 3, there was a significant increase in the daily average concentration of $\mathrm{PM}_{10}$ and 
$183 \mathrm{PM}_{2.5}$ in all the stations of Mexico under the examination period of Saharan dust event $\left(23^{\text {rd }}\right.$ to $18429^{\text {th }}$, June 2020). The elevated PM concentrations were as a result of received Saharan dust cover 185 which is generally a rich source of $\mathrm{PM}_{10}$ and $\mathrm{PM}_{2.5}$. TAS and VAS 2 stations recorded the highest 186 daily average concentration of $197 \mu \mathrm{g} / \mathrm{m}^{3}$ and $94 \mu \mathrm{g} / \mathrm{m}^{3}$ for $\mathrm{PM}_{10}$ and $\mathrm{PM}_{2.5}$, respectively. In 187 contrast, MAS 6 and MAS 10 stations registered the lowest daily average concentration of 49 $188 \mu \mathrm{g} / \mathrm{m}^{3}$ and $35 \mu \mathrm{g} / \mathrm{m}^{3}$ for $\mathrm{PM}_{10}$ and $\mathrm{PM}_{2.5}$, respectively. After the dust event, a considerable decrease 189 in the PM concentrations (Fig. 2 and 3) was noted but the concentration of $\mathrm{PM}_{10}$ and $\mathrm{PM}_{2.5}$ 190 remained high to those observed before the event. It can be explained by the fact that the effect of 191 a Saharan dust event can extend to days succeeding the event as fine particulates can remain 192 airborne for long durations.

193 Considering all days, $\mathrm{PM}_{10}\left(\mu \mathrm{g} / \mathrm{m}^{3}\right)$ average concentrations were 47, 42 and 53 for Nuevo 194 Leon, Veracruz and Tabasco; $\mathrm{PM}_{2.5}\left(\mu \mathrm{g} / \mathrm{m}^{3}\right)$ average concentrations were 20, 24 and 25 for Nuevo 195 Leon, Veracruz and Yucatan, respectively. It is noted that the increase in the concentration of PM 196 was more significant on Saharan dust days as compared with the non-Saharan dust days. On 197 Saharan dust days, average concentrations were 1.2, 2.2 and 2.2 times higher for $\mathrm{PM}_{10}$ than on 198 non-Saharan dust days, with the values reaching $52 \mu \mathrm{g} / \mathrm{m}^{3}, 68 \mu \mathrm{g} / \mathrm{m}^{3}$ and $86 \mu \mathrm{g} / \mathrm{m}^{3}$ for Nuevo Leon, 199 Veracruz and Tabasco, respectively. Compared to non-Saharan dust days, the average 200 concentrations of $\mathrm{PM}_{2.5}$ were 1.3, 1.8 and 2.4 times higher for Nuevo Leon, Veracruz and Yucatan, 201 with the values reaching $25 \mu \mathrm{g} / \mathrm{m}^{3}, 37 \mu \mathrm{g} / \mathrm{m}^{3}$ and $44 \mu \mathrm{g} / \mathrm{m}^{3}$, respectively. The results suggest that 202 Tabasco and Yucatan have the highest average value of $\mathrm{PM}_{10}$ and $\mathrm{PM}_{2.5}$, followed by Veracruz 203 and Nuevo Leon.

204 Next, we estimated the changes (\%) in $\mathrm{PM}_{10}$ and $\mathrm{PM}_{2.5}$ concentrations for the period of 205 assessment i.e. non-Saharan dust vs Saharan dust (Fig. 4). The first thing to note is that the 
206 variations of PM concentrations were obvious among the study regions, but it was uneven. The 207 stations located in the coastal regions of Tabasco, Veracruz and Yucatan presented higher increase 208 percentage of PM levels in Saharan dust days than non-Saharan days. The station that registered 209 the greatest change percentage was VAS 1 (118\%), followed by TAS (115\%) for PM10. YAS 210 station recorded a maximum increase of about $59 \%$ for $\mathrm{PM}_{2.5}$. In contrary, the increase percentage 211 of $\mathrm{PM}_{10}$ and $\mathrm{PM}_{2.5}$ concentrations varied between $5 \%$ and $45 \%$, respectively, in Nuevo Leon, 212 displaying an overall increase of $20 \%$ of PM levels for the study period. For example, the increase 213 of PM levels was higher in MAS 2 and MAS 1 between Saharan dust days and non-Saharan days, 214 while it was least significant in MAS 10 station (Fig. 4). MAS 8 station displayed no significant 215 variation between non-Saharan and Saharan dust days. It can be said that Nuevo Leon (located 216 northeast) is less affected by Saharan dust event compared to other regions that are located on the 217 southeast side of Mexico. This may be likely due to the differences in the dust intensity 218 (significantly thicker dust), gravitational settling velocities and distribution of Saharan dust across 219 Mexico.

220 Additionally, the changes (\%) in $\mathrm{PM}_{10}$ and $\mathrm{PM}_{2.5}$ concentrations were examined with 221 respect to previous major Saharan dust episodes in Mexico (Table 2). The lack of data availability 222 from few air monitoring stations for previous year events, however, rendered a complete 223 comparison to understand the effect of $\mathrm{PM}_{10}$ and $\mathrm{PM}_{2.5}$ concentrations between Saharan dust 224 episodes. With available data, the first thing to note is that the $\mathrm{PM}_{10}$ and $\mathrm{PM}_{2.5}$ concentrations did 225 not show similar trends in each of the Saharan dust episodes. Despite certain differences observed 226 in the concentrations, it is seen in Table 2 that all stations exceeded the concentrations of $\mathrm{PM}_{10}$ 227 and $\mathrm{PM}_{2.5}$ with those of 2015, 2018 and 2019, except for MAS 1. The change was noticeable with 228 considerable increase, and it was well pronounced compared to previous Saharan dust episodes. 
229 For example, an average increase of $\mathrm{PM}_{10}$ by $8 \%$ and $71 \%$ was noted compared to years 2018 and 2302019 in Nuevo Leon; in contrary, $\mathrm{PM}_{2.5}$ increased by $166 \%$ compared to 2019 . When comparing 2312019 with 2020, VAS1 and VAS2 stations recorded $124 \%$ and $202 \%$ increase of $\mathrm{PM}_{2.5}$. The result 232 of the analysis confirmed that the observed changes in the $\mathrm{PM}_{10}$ and $\mathrm{PM}_{2.5}$ concentrations are more 233 severe during the June 2020 Saharan dust compared to previous episodes in Mexico.

234 It is reasonable to assume that the amount of dust entering the atmosphere in the region 235 could worsen by the increased particulate concentrations. Therefore, it is critical to estimate air 236 quality index for the Saharan dust period. As shown in Fig. 5, in general, the distribution of air 237 quality trend between the stations for $\mathrm{PM}_{10}$ remained good for most of the days but based on $\mathrm{PM}_{2.5}$,

238 the dominance of moderate category was observed. In terms of $\mathrm{PM}_{2.5}$ estimations, it is suggested 239 that the population of study area is exposed with more than 50\% of the days with significant impact 240 on health. It is important to note an elevated value in the category, "unhealthy" for all the stations 241 on the maximum dusty day (June 27), leading to adverse air quality. The consequences of these 242 inflations in air quality might have impact on health, especially on elderly and sensitive groups 243 during COVID-19 pandemic.

244 Similar to our findings, variations in $\mathrm{PM}_{10}$ and $\mathrm{PM}_{2.5}$ levels during the Saharan dust events 245 especially in the proximity of the source areas have been widely reported. Spain and Nicosia 246 displayed $\mathrm{PM}_{10}$ concentrations reaching $250 \mu \mathrm{g} / \mathrm{m}^{3}$ and up to $470 \mu \mathrm{g} / \mathrm{m}^{3}$ respectively, during 247 Saharan dust events (Querol et al. 2009; Achilleos et al. 2014). Moroni et al. (2015) identified 22 248 dust intrusions in Monte Martano (central Italy) in 2009, and estimated the impact of dust on PM $\mathrm{PM}_{10}$ 249 at $22 \mu \mathrm{g} / \mathrm{m}^{3}$ per intrusion. Kabatas et al. (2014) also found a significant contribution of dust to high 250 levels of $\mathrm{PM}_{10}$ in Turkey. Likewise, Dimitriou and Kassomenos (2018) observed extreme 251 concentrations of $\mathrm{PM}_{10}$ in Athens (Greece) during April 2008 Saharan dust. We acknowledge here 
252 that our results of PM levels in Mexico were way lower compared to other regions during Saharan

253 dust episodes (i.e. 2015, 2018, 2019 and 2020) due to its geographical location away $(\sim 7,000 \mathrm{~km})$

254 from the source area. In addition, the lack of investigations for North American region closer to 255 our study area, however, hinders a detailed comparison.

Owing to the fact that the COVID-19, by itself a respiratory disease and spread quickly

257 among the community and SARS-CoV-2 would remain viable and infectious in aerosols for hours

258 (van Doremalen et al. 2020), this study determined the possible interrelationship between PM and

259 COVID-19 cases and deaths for Nuevo Leon. By July 12, 2020, Nuevo Leon reported 12322

260 confirmed COVID-19 cases and 694 deaths (Government of Mexico:

261 https://coronavirus.gob.mx/datos/). The correlation analysis was performed for the entire study 262 period (June 15, 2020 to July 12, 2020) considering the longer residence of PM levels in the 263 atmosphere after the dust event (Fig. 2 and 3). Table 3 summarizes the association between PM 264 and COVID-19 cases and death for the study period. Our results provided preliminary evidences 265 showing that there is a prominent association of PM with COVID-19 cases and deaths during the 266 Saharan dust event but only that of $\mathrm{PM}_{10}$ is significant. The fine fraction of $\mathrm{PM}\left(\mathrm{PM}_{2.5}\right)$ in our case 267 did not present a substantial relation with COVID-19 cases and deaths (Table 3). Few studies 268 reported similar results of less statistically significant association of $\mathrm{PM}_{2.5}$ particles with total or 269 specific mortality. For example, in Barcelona (Spain) the effects of short-term exposure to $\mathrm{PM}_{2.5}$ 270 was not significant during Saharan dust days (Perez et al., 2008). It was found, in Madrid and Italy, 271 that the daily mean $\mathrm{PM}_{2.5}$ concentrations displayed no statistically significant association with total 272 mortality, circulatory and respiratory causes on Saharan dust days (Jiménez et al. 2010; Tobías et 273 al. 2011; Mallone et al. 2011). Under reduced anthropogenic activities during pandemic measures, $274 \mathrm{PM}_{10}$ have presented strong relationship with COVID-19 mortality rate in many parts of the world 
275 (Yao et al. 2020; Setti et al. 2020; Shakoor et al. 2020; Kutralam-Muniasamy et al. 2020).

276 Similarly, in this study, $\mathrm{PM}_{10}$ is positively correlated with COVID-19 cases and deaths $\left(r^{2}=0.53\right.$;

277 0.50), suggesting exposure to such PM levels may affect COVID-19 prognosis and thus, more

278 comprehensive studies should be conducted on this subject.

279 Furthermore, to understand the human health risks associated with PM exposure during the

280 study period, non-carcinogenic and carcinogenic risks in both children and adults via inhalation

281 for Saharan dust and non-Saharan dust days were estimated by calculating the average CDI and

282 HQ. The results are shown in Table 4. It can be seen that the CDI values for non-carcinogenic risk

283 of PM in children were comparatively higher than adults during Saharan period. For instance, the

284 maximum CDI values $\left(\mu \mathrm{g} \mathrm{kg}^{-1} \mathrm{day}^{-1}\right)$ of non-carcinogenic risk for $\mathrm{PM}_{10}$ and $\mathrm{PM}_{2.5}$ in children was

2854.4 and 0.38 (Tabasco), while for adults was only 2.48 (Tabasco) and 1.16 (Yucatan), respectively.

286 It has been documented that children are highly vulnerable to environmental pollutants than adults

287 for numerous reasons, including their relatively higher amount of air inhalation (the air intake per

288 weight unit of a resting infant is twice that of an adult), and their immune system and lungs not

289 being fully developed (Thabethe et al. 2014; Morakinyo et al. 2017). Contrarily, for carcinogenic

290 risks, adults displayed maximum CDI values $\left(\mu \mathrm{g} \mathrm{kg}^{-1} \mathrm{day}^{-1}\right)$ of 0.85 (Tabasco) and 0.40 (Yucatan),

291 and children exhibited 0.38 (Tabasco) and 0.18 (Yucatan) values for $\mathrm{PM}_{10}$ and $\mathrm{PM}_{2.5}$. Among

292 regions studied, Veracruz, Tabasco and Yucatan during Saharan dust days presented nearly

293 onefold to two-fold increase in CDI values for both children and adults compared to non-Saharan

294 dust days. Nuevo Leon also presented greater CDI values; however, it was in lesser extent

295 compared to other regions. As mentioned earlier in this study, it could be attributed to the location

296 of Nuevo Leon (northeast), which experienced lesser impact from Saharan dust event in

297 comparison with other three regions (southeast) in Mexico. In case of HQ, both children and adults 
298 displayed values higher for $\mathrm{PM}_{2.5}$ compared to $\mathrm{PM}_{10}$ (Table 4). It is important to mention here that 299 the AQI values for $\mathrm{PM}_{2.5}$ fell into the category of moderate-unhealthy for most Saharan dust days. 300 Fine fraction of PM particles $\left(\mathrm{PM}_{2.5}\right)$ are more resident in the atmosphere and they more easily 301 penetrate the respiratory system (Xing et al. 2016) which is a deep concern and demands in depth 302 investigation of health risks associated with $\mathrm{PM}_{2.5}$. In general, HQ values were similar on non303 Saharan days, whereas a potential increase in HQ values closer to 1 was seen in all the four studied 304 regions during Saharan dust days. Therefore, our results from human health risk assessment about 305 the levels and risks of PM could make useful contributions to government, environmental and 306 health professionals in taking good steps to protect and promote human health during this 307 pandemic situation.

\section{4. Limitations of the study}

Although our study data and correlational analysis showed significant impacts of PM from

310 Saharan dust in COVID-19, this short communication has a few limitations: - (1) Additional

311 information on meteorological factors such as temperature, precipitation and relative humidity

312 were not examined, and future studies need to explore these factors for a comprehensive

313 investigation. (2) PM samples from the June 2020 Saharan dust event were not analyzed by

314 scanning electron microscopy with energy dispersive X-ray spectrometry and inductively coupled

315 plasma mass spectrometry for morphological and chemical characterization. These results would 316 have been greatly helpful but could not be accomplished as the COVID-19 pandemic hindered the 317 analyses. Accordingly, the chemical composition of PM was not taken into account for assessing 318 the health associated risks and as a result, the exposure to the combination of the pollutants could 319 not be determined. Thus, the toxic effects of these PM particles during the short-term dust episodes

320 should be further investigated. (3) This study could not consider population density, mobility 
321 trends from the regions studied in the analysis. Future studies can investigate on these aspects to

322 provide more useful insights into the spread of COVID-19. (4) The lack of studies for comparison

323 demands future studies from other world regions that are similarly affected by the June 2020

324 Saharan dust event.

\section{5. Concluding remarks}

326 In summary, this study is the first to quantitatively assess the importance of the June 2020

327 Saharan dust event over PM concentrations in Mexico, as well to investigate its relationship with

328 COVID-19 pandemic. As a consequence of the June 2020 Saharan dust event, we observed a

329 sudden hike in both $\mathrm{PM}_{10}$ and $\mathrm{PM}_{2.5}$ concentrations from northeastern and southeastern regions of

330 Mexico. Also, in these regions, the PM levels were higher in many orders of magnitude compared

331 to previous major Saharan dust episodes. Based on our results, it is confirmed that the Saharan

332 dust transported from longer distances had a significant effect on the PM concentrations in Mexico.

333 The correlational analysis revealed that the Saharan dust contributions to increased $\mathrm{PM}_{10}$ levels

334 present positive association with the daily number of COVID-19 confirmed cases and deaths. In

335 parallel, this study provided a valuable evaluation of the human health risks associated with

336 exposure to PM via inhalation in both children and adults during the dust event. Overall, the main

337 findings of this study underline that the Saharan dust events cannot be ignored during global health

338 crisis. Taking together, this study could serve as a reference data for government authorities to 339 design appropriate strategies for mitigating such unforeseen episodes to improve air quality.

\section{Ethics approval and consent to participate}

341 Not applicable.

\section{Consent for publication}

343 Not applicable. 


\section{Availability of data and materials}

The datasets generated and/or analysed during the current study are available in the Sistema

346 Nacional de Información de la Calidad del Aire repository, operated by Instituto Nacional de

347 Ecologia y Cambio Climatico, Government of Mexico (SINAICA, 348 https://sinaica.inecc.gob.mx/index.php).

\section{Conflicts of Interest / Competing Interests}

350 The authors declare that they have no competing interests.

$351 \quad$ Funding

352 Not applicable.

353 Author's contribution

354 V.C. Shruti - Conceptualization, Methodology, Data curation, Writing - original draft,; 355 Gurusamy Kutralam-Munaisamy - Conceptualization, Methodology, Data curation, Writing 356 original draft; Fermín Pérez-Guevara - Methodology, Conceptualization; I. Elizalde Martinez 357 Supervision.

358 Acknowledgements

359 VCS thanks CONACYT project no. 274276 "Fase I De La Remediación de Áreas 360 Contaminadas Con Hidrocarburos En La Refinería Gral. Lázaro Cárdenas" for Postdoctoral 361 fellowship. The authors would like to acknowledge all the doctors, health-care professionals, 362 police personnel, sanitation workers and waste collectors at the frontlines working silently and 363 tirelessly during COVID-19 outbreak world-wide. We also thank Sistema Nacional de 364 Información de la Calidad del Aire, operated by Instituto Nacional de Ecologia y Cambio 365 Climatico, Government of Mexico for making air quality data open access.

\section{References}


Achilleos S, Evans JS, Yiallouros PK, Kleanthous S, Schwartz J, Koutrakis P (2014) PM10 concentration levels at an urban and background site in Cyprus: the impact of urban sources and dust storms. J Air Waste Manag Assoc 64(12):1352-60

Ali-Khodja H, Kadja M, Terrouche A, Lokorai K (2017) Identification of anthropogenic and natural sources of atmospheric particulate matter and trace metals in Constantine, Algeria. J Earth Sci. Geotech. Eng. 7(1):231-40.

Bretón RM, Bretón JG, Kahl J, Lara ER, Quiroz AV, Guzmán AA, García MM, Hernández GG, Canul JA, Guzmán AR (2018) Atmospheric N and S Deposition Fluxes in the 375 Metropolitan Area of Monterrey, Mexico and Its Relation with Criteria Air Pollutants and Meteorological Conditions. InAir Pollution-Monitoring, Quantification and

Çapraz Ö, Deniz A (2020) Particulate matter (PM 10 and PM 2.5) concentrations during a Saharan Removal of Gases and Particles. IntechOpen dust episode in Istanbul. Air Qual Atmos Health 1-8

Coker ES, Cavalli L, Fabrizi E, Guastella G, Lippo E, Parisi ML, Pontarollo N, Rizzati M, Varacca A, Vergalli S (2020) The Effects of Air Pollution on COVID-19 Related Mortality in Northern Italy. Environ Resour Econ 76(4):611-634 Risk assessment of PM 2.5 to child residents in Brazilian Amazon region with biofuel production. Environ Health 11(1):1-11

Dimitriou K, Kassomenos P (2018) Day by day evolution of a vigorous two wave Saharan dust storm-Thermal and air quality impacts. Atmósfera 31(2):105-124 
DOF (Diario Oficial de la Federación) (2014) Valores límites permisibles para la concentración

391

392

393

394

395

396

397

398

399

400

401

402

403

404

405

406

407

408

409

410

411

de partículas suspendidas PM10 y PM2.5 en el aire ambiente y criterios para su evaluación. Norma Oficial Mexicana NOM-025-SSA1-2014. Available online: http://www.aire.cdmx.gob.mx/descargas/monitoreo/normatividad/NOM-025SSA1-2014.pdf

González-Santiago O, Badillo-Castaneda CT, Kahl JD, Ramírez-Lara E, Balderas-Renteria I (2011) Temporal analysis of PM10 in metropolitan Monterrey, México. J Air Waste Manag Assoc 1,61(5):573-9

Hernández-Escamilla JA, Flores-Margez JP, Shukla MK (2015) Particulate matter: capture and quantification in natural and anthropogenic sources. $J$ Environ Anal Toxicol 5(281):2161-0525

Jiménez E, Linares C, Martínez D, Díaz J (2010) Role of Saharan dust in the relationship between particulate matter and short-term daily mortality among the elderly in Madrid (Spain). Sci Total Environ 408(23):5729-5736

Kabatas B, Unal A, Pierce RB, Kindap T, Pozzoli L (2014) The contribution of Saharan dust in PM10 concentration levels in Anatolian Peninsula of Turkey. Sci Total Environ 488489:413-421

Kim KH, Kabir E, Kabir S (2015) A review on the human health impact of airborne particulate matter. Environ Int 74:136-143

Kutralam-Muniasamy G, Pérez-Guevara F, Roy PD, Elizalde-Martínez I, Shruti VC (2020) Impacts of the COVID-19 lockdown on air quality and its association with human mortality trends in megapolis Mexico City. Air Qual Atmos Health 28:1-0 
412 Li F, Xiao M, Zhang J, Yang J, Zhu L (2017) Health risk assessment on tunnel workers' exposure to PM10 based on triangular fuzzy numbers. In AIP conference proceedings. 1820(1):040011

415 Loxham M, Nieuwenhuijsen MJ (2019) Health effects of particulate matter air pollution in underground railway systems-a critical review of the evidence. Particle Fibre Toxicol $16(1): 1-24$

Mallone S, Stafoggia M, Faustini A, Gobbi GP, Marconi A, Forastiere F (2011) Saharan dust and Health Perspect 119(10):1409-1414

421 Molina LT, Velasco E, Retama A, Zavala M (2019) Experience from integrated air quality management in the Mexico City metropolitan area and Singapore. Atmosphere 10:512

423 Morakinyo OM, Adebowale AS, Mokgobu MI, Mukhola MS (2017) Health risk of inhalation exposure to sub-10 $\mu \mathrm{m}$ particulate matter and gaseous pollutants in an urban-industrial

Moroni B, Castellini S, Crocchianti S, Piazzalunga A, Fermo P, Scardazza F, Cappelletti D, (2015) Ground-based measurements of long-range transported aerosol at the rural regional

429 Perez L, Tobias A, Querol X, Künzli N, Pey J, Alastuey A, Viana M, Valero N, González-Cabré M, Sunyer J (2008) Coarse particles from Saharan dust and daily mortality. Epidemiology 800-807 the Mediterranean Basin. Atmos. Environ. 43:4266-4277 
Querol X, Tobías A, Pérez N, Karanasiou A, Amato F, Stafoggia M, García-Pando CP, Ginoux P, Forastiere F, Gumy S, Mudu P (2019) Monitoring the impact of desert dust outbreaks for air quality for health studies. Environ. Int. 130:104867

Setti L, Passarini F, De Gennaro G, Barbieri P, Perrone MG, Piazzalunga A, Borelli M, Palmisani J, Di Gilio A, Piscitelli P, Miani A (2020) The Potential Role of Particulate Matter in the Spreading of COVID-19 in Northern Italy: First Evidence-Based Research Hypotheses. https://www.medrxiv.org/content/10.1101/2020.04.11.20061713v1

Shakoor A, Chen X, Farooq TH, Shahzad U, Ashraf F, Rehman A, e Sahar N, Yan W (2020) Fluctuations in environmental pollutants and air quality during the lockdown in the USA and China: two sides of COVID-19 pandemic. Air Qual Atmos Health 1-8

Thabethe NDL, Engelbrecht JC, Wright CY, Oosthuizen MA (2014) Human health risks posed by exposure to PM10 for four life stages in a low socio-economic community in South Africa. Pan Afri. Med. J. 18

Tobías A, Pérez L, Díaz J, Linares C, Pey J, Alastruey A, Querol X (2011) Short-term effects of particulate matter on total mortality during Saharan dust outbreaks: a case-crossover analysis in Madrid (Spain). Sci Total Environ. 412:386-389

USEPA (1989) Risk Assessment Guidance for Superfund (RAGS): Human health evaluation manual (Part F), Office of Solid Waste Emergency Response, Washington DC, America USEPA (1999) Guideline for reporting of daily air quality -Air Quality Index (AQI). Office for Air Quality Planning and Standards, United States Environmental Protection Agency, North Carolina, USA. http://www.epa.gov/ttn/-oarpg/t1/memoranda/rg701.pdf. 
USEPA (2002) Calculating upper confidence limits for exposure point concentrations at hazardous waste sites OSWER 92856-10Washington, DC: Office of Emergency and Remedial Response, US Environmental Protection Agency; 20460, December 2002

USEPA (2009) Risk assessment guidance for superfund. In: Human Health Evaluation Manual

USEPA (2011) Exposure factors handbook 2011 edition EPA/600/R-09/052F Washington, DC:

National Center for Environmental Assessment, Office of Research and Development,

van Doremalen N, Bushmaker T, Morris DH, HolbrookMG, Gamble A, Williamson BN, Tamin

WHO (2006) Air Quality Guidelines, Global Update 2005; World Health Organization: Geneva, 2006

p. 22. Available online: https://www.who.int/phe/health_topics/outdoorair/outdoorair_aqg/en/

WHO (2018) http://www.who.int/news-room/detail/02-05-2018-9-out-of-10-people-worldwidebreathe-polluted-air-but-more-countries-are-taking-action

19). https://www.who.int/docs/default-source/coronaviruse/who-china-joint-missionon-covid-19-final-report.pdf 
479 Xing YF, Xu YH, Shi MH, Lian YX (2016) The impact of PM2. 5 on the human respiratory system. J Thorac. Dis. 8(1): E69

481 Yao Y, Pan J, Wang W, Liu Z, Kan H, Meng X, Wang W (2020) Spatial correlation of particulate matter pollution and death rate of COVID19/China/PM25. PM10/multiple linear regression medRxiv https://doi.org/10.1101/2020.04.07.20052142

484 Yunesian M, Rostami R, Zarei A, Fazlzadeh M, Janjani H (2019) Exposure to high levels of PM2. 5 and PM10 in the metropolis of Tehran and the associated health risks during 20162017. Microchemical J. 150: 104174

\section{$487 \quad$ Figure legends}

488 Figure 1 (a) Dust forecast obtained from the NASA GEOS-5 Model showing the June 2020

489 Saharan dust event. (b) Map showing the study regions for the demonstration of Saharan dust event 490 in Mexico.

491 Figure 2 Average $\mathrm{PM}_{10}$ concentrations from June 15 to July 12, 2020 recorded in air monitoring 492 stations located in Nuevo Leon, Veracruz and Tabasco of Mexico.

493 Figure 3 Average $\mathrm{PM}_{2.5}$ concentrations from June 15 to July 12, 2020 recorded in air monitoring 494 stations located in Nuevo Leon, Veracruz and Yucatan of Mexico.

495 Figure 4 Bar chart displaying the changes (\%) in PM concentrations between non-Saharan and 496 Saharan days.

497 Figure 5 AQI levels for $\mathrm{PM}_{10}$ and $\mathrm{PM}_{2.5}$ concentration for the period of assessment (June 23 - 29, 498 2020).

\section{Table legends}

500 Table 1 List of air monitoring stations from the Saharan dust affected regions for the period of 501 assessment (June 15 - July 12, 2020) in Mexico. 
502 Table 2 Comparison of PM concentrations between Saharan dust episodes for years 2015, 2018, 5032019 and 2020 in Mexico.

504 Table 3 Correlation between daily confirmed COVID-19 cases and deaths and particulate matter 505 in Nuevo Leon (Mexico).

506 Table 4 Health risk assessment for PM exposure via inhalation during the June 2020 Saharan

507 dust event in Mexico. 


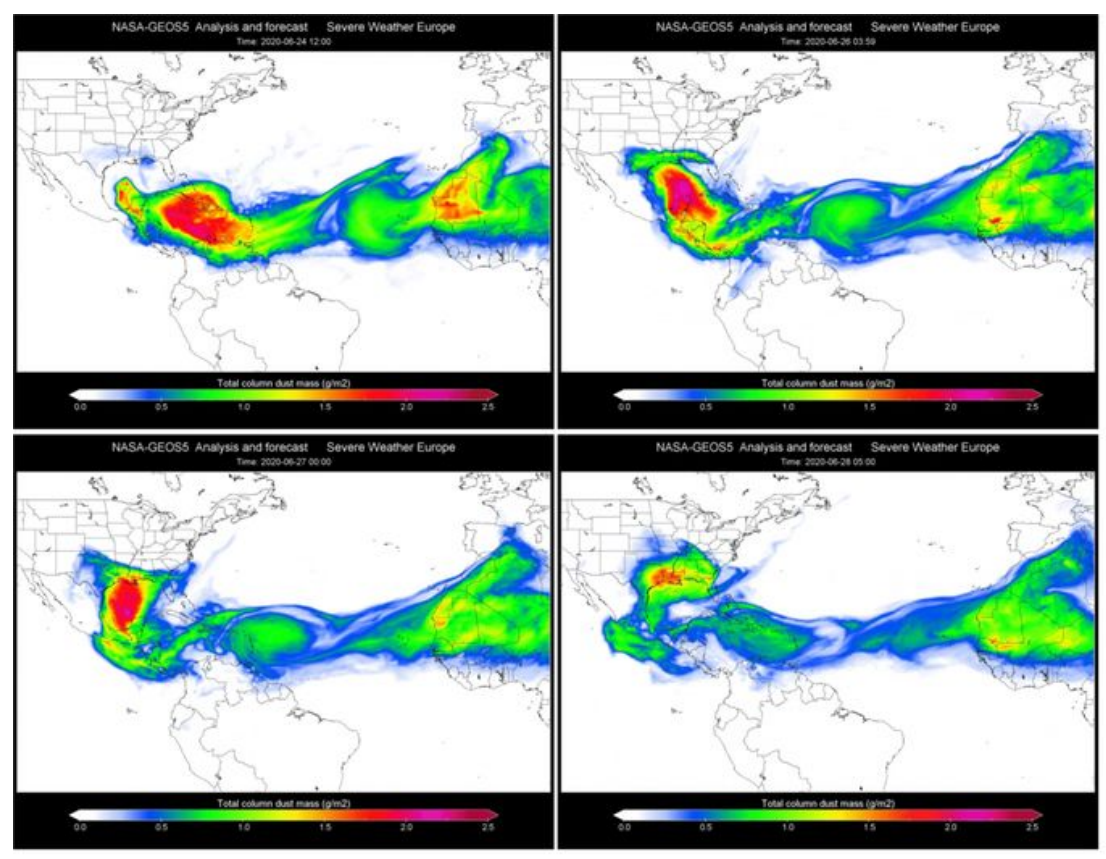

(a)

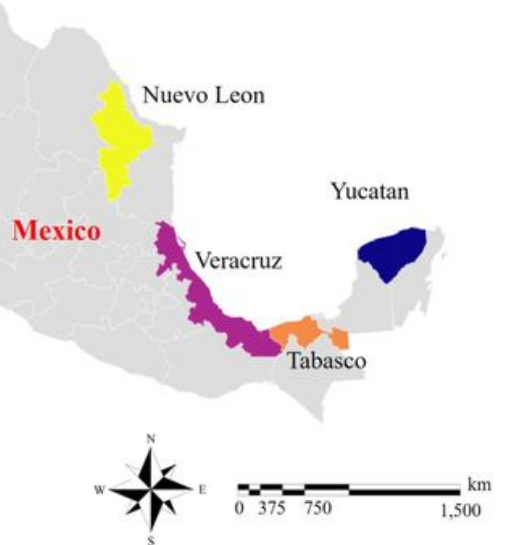

(b)

\section{Figure 1}

(a) Dust forecast obtained from the NASA GEOS-5 Model showing the June 2020 Saharan dust event. (b) Map showing the study regions for the demonstration of Saharan dust event in Mexico. Note: The designations employed and the presentation of the material on this map do not imply the expression of any opinion whatsoever on the part of Research Square concerning the legal status of any country, territory, city or area or of its authorities, or concerning the delimitation of its frontiers or boundaries. This map has been provided by the authors.
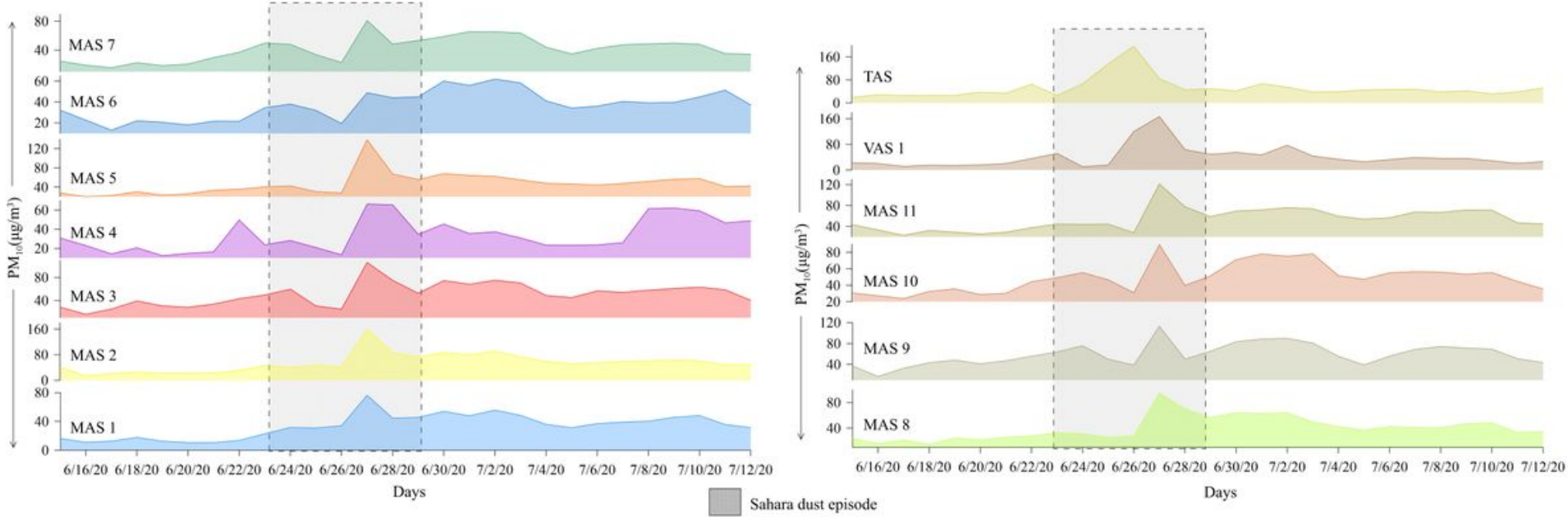

Figure 2 
Average PM10 concentrations from June 15 to July 12, 2020 recorded in air monitoring stations located in Nuevo Leon, Veracruz and Tabasco of Mexico.

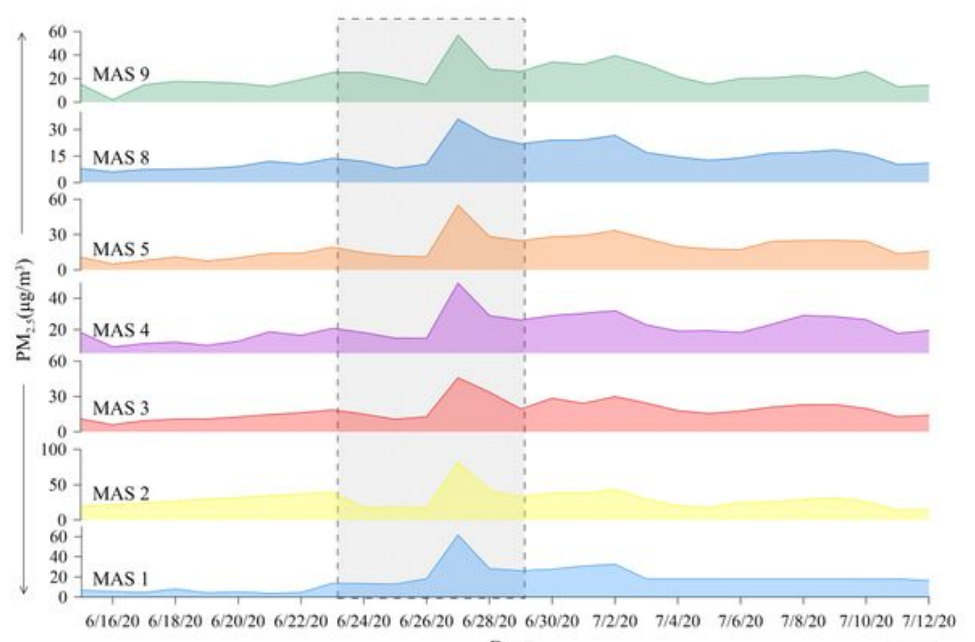

Days

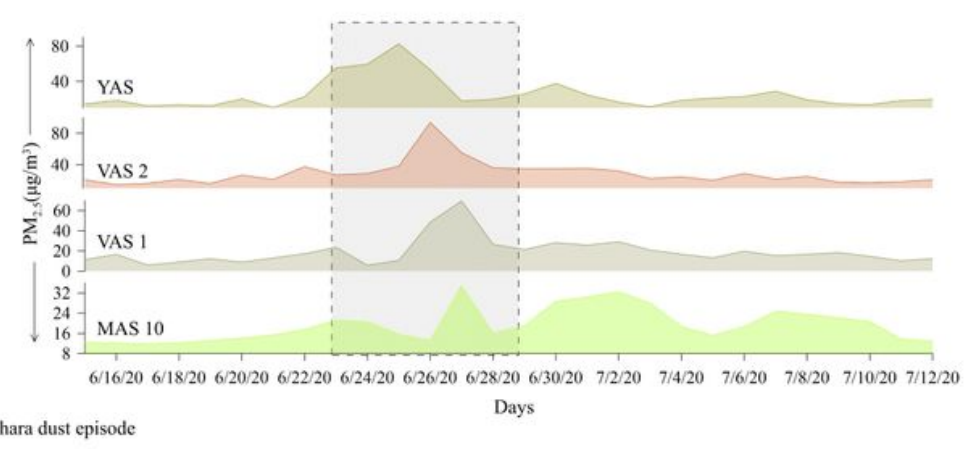

\section{Figure 3}

Average PM2.5 concentrations from June 15 to July 12, 2020 recorded in air monitoring stations located in Nuevo Leon, Veracruz and Yucatan of Mexico. 


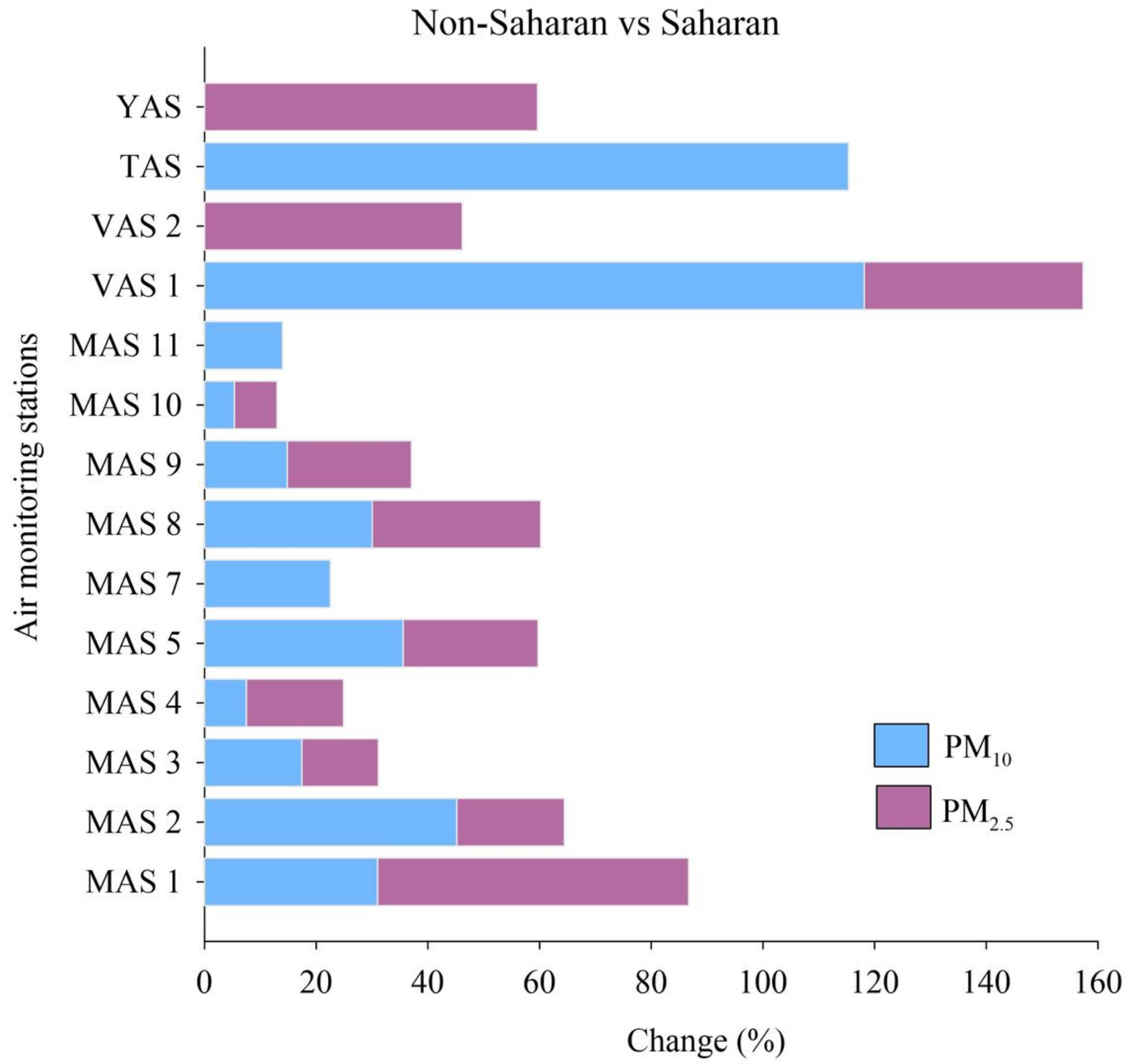

Figure 4

Bar chart displaying the changes (\%) in PM concentrations between non-Saharan and Saharan days. 
(a)

\begin{tabular}{|c|c|c|c|c|c|c|c|}
\hline \multirow{14}{*}{$\begin{array}{r}\text { MAS } 1 \\
\text { MAS } 2 \\
\text { MAS } 3 \\
\text { MAS 4 } \\
\text { MAS 5 } \\
\text { MAS 6 } \\
\text { MAS 7 } \\
\text { MAS 8 } \\
\text { MAS 9 } \\
\text { MAS } 10 \\
\text { MAS } 11 \\
\text { VAS } 1 \\
\text { TAS }\end{array}$} & 20 & 29 & 29 & 31 & 61 & 41 & 42 \\
\hline & 42 & 37 & 43 & 39 & 103 & 66 & 59 \\
\hline & 45 & 53 & 28 & 23 & 76 & 61 & 48 \\
\hline & 21 & 26 & 19 & 12 & 56 & 56 & 31 \\
\hline & 37 & 39 & 28 & 25 & 92 & 57 & 51 \\
\hline & 31 & 35 & 30 & 18 & 44 & 41 & 41 \\
\hline & 45 & 44 & 31 & 20 & 64 & 44 & 49 \\
\hline & 31 & 29 & 23 & 25 & 71 & 58 & 51 \\
\hline & 55 & 61 & 46 & 35 & 80 & 46 & 56 \\
\hline & 45 & 49 & 43 & 28 & 68 & 36 & 47 \\
\hline & 41 & 40 & 41 & 25 & 84 & 62 & 52 \\
\hline & 47 & 9 & 14 & 83 & 107 & 55 & 44 \\
\hline & 23 & 56 & 91 & 122 & 65 & 42 & 45 \\
\hline & $23 / 06 / 2020$ & $24 / 06 / 2020$ & $25 / 06 / 2020$ & $26 / 06 / 2020$ & $27 / 06 / 2020$ & $28 / 06 / 2020$ & $29 / 06 / 2020$ \\
\hline
\end{tabular}

(b)



UHS: unhealthy for sensitive groups

\section{Figure 5}

AQI levels for PM10 and PM2.5 concentration for the period of assessment (June $23-29,2020$ ).

\section{Supplementary Files}

This is a list of supplementary files associated with this preprint. Click to download.

- GA.pdf 